physical signs, there was no room for doubt that this was due to the existence of a tumour within the thorax. The subsequent enlargement of the cervical glands, and the distension of the superficial veins (which, however, was not at any time very marked), gave additional confirmation to this view. We could judge, also, from the course of the case, and the mode of evolution of the symptoms, that the new growth had commenced in the posterior part of the mediastinum-involving first the bifurcation of the trachea and the osophagus, then extending forward to the neighbourhood of the large vessels, implicating the left recurrent nerve, and finally beginning to exercise slight pressure upon the large veins. Had the tumour commenced its growth in the anterior part of the mediastinum we should probably have had symptoms of venous pressure developed early, and the evidences of pressure on the recurrent nerve, on the trachea and oesophagus, might have supervened late in the history of the case.

The clinical history of intra-thoracic growths, upon which so much light has been thrown by the able researches of Dr. Risdon Bennett, has now attained considerable com. pleteness, and their diagnosis, hitherto confessedly so difficult, is at present approaching something like precision and certainty. The tendency of many of these cases to simulate, as this one did, the clinical aspects of somewhat rapid phthisis, has been pointed out by Dr. Risdon Bennett, Sir Thomas Watson,* Dr. Murchison, and others; but I am not aware that anyone, in this country at least, has hitherto demonstrated a paralytic affection of the vocal cords as observed accompanying intra-thoracic cancer. Dr. H. Rendu, however, in an able summary of what has been written on the subject of malignant tumours of the mediastinum, in the Archives Générales de Médecine, 1875, mentions Rossbacht as having published some cases "altogether exceptional," in which "temporary aphonia" was an early symptom. He adds: "This observation of Rossbach I believe to be unique up to the present time; and this mode of début must at any rate be very rare, for in the regular course of mediastinal tumours the pneumogastric nerves and the recurrents are ordinarily the last to be invaded, and for a very long time they escape the causes of compression."

It has been said that in these cases of mediastinal tumour the patients usually complain of a fixed, circumscribed pain behind the upper third of the sternum, and that this is of diagnostic value, and precedes the other symptoms. In the above case, and in another case of intra-thoracic cancer which I published in March, 1875, there was never any complaint of local pain while the patients were under observation. It has also been noticed that the appearance of blood in the expectoration is usually significant, as it was in this case, of the secondary formation of cancerous nodules within the lung itself. The chief point of interest, however, in this case, and that to which I wish to call attention in placing it on record, is the aid which was afforded us in our diagnosis by the use of the laryngoscope, whereby we were enabled at once to discover that the loss of voice was not caused by intrinsic disease of the larynx itself, but by disease within the thorax interfering with the innervation of the laryngeal muscles.

\section{THE TREATMENT OF ACUTE RHEUMATISM BY SALICIN.}

\section{BY JOHN CURNOW, M.D. LOND.,}

PRONRSSOE OF ANATONY IN FING'S COLLEGE, AND ASEIFTANT-PHYSICIAN TO KING'S COLLEGE HOSPITAL.

THE treatment of acute rheumatism is so varied and unsatisfactory, that any new method or novel therapeutic agent is sure of attracting much attention, and the discovery of any means of arresting the course or diminishing the complications of so common and perilous an affection cannot be too highly appreciated. Dr. Maclagan's success with salicin is so very remarkable that it is incumbent on other physicians to state their experience of this remedy. Whilst in temporary charge of the medical wards at the Seamen's Hospital, I treated four cases of well-marked rheumatic fever on this plan, and I purpose giving a short abstract of these cases and the results. I am indebted to Mr. A. G. Lacy, the acting house-physician, for the notes. CASE 1.-R. W. V-—, aged twelve, was admitted on May 1st, 1876, with considerable effusion into both knees and ankles, and complaining of great pain and tenderness in those joints and in the hips. He presented the ordinary symptoms of a moderately severe attack of acute rheumatism, and had been ill for six or geven days previously. A systolic bruit was plainly audible over the apex of the heart, but this was probably due to a former attack from which he had suffered four years previously. His temperature was $101^{\circ}$ on admission, $101.4^{\circ}$ at night, and $102^{\circ}$ on the following morning. He was then ordered salicin in ten-grain doses every two hours. Two days after the administration of the remedy his temperature fell to $99^{\circ}$, and the pain was much less, and in five days from his admission he was practically convalescent.

CASE 2.-J. H- a - aged twenty-three, was admitted on Iune 19th, 1876, with an attack of much the same severity as the preceding. He had been ill for two days only, and the joints affected were the knees, ankles, and wrists. His temperature on admission was $1006^{\circ}$; it rose at night to $101 \cdot 2^{\circ}$, and the next morning and evening was at $101 \cdot 6^{\circ}$ and 102 $2^{\circ}$ respectively. From this time he began to improve. His temperature fell to $101^{\circ}$ and became normal on the sixth day after admission. Salicin in ten-grain doses every two hours was administered from bis admission. There was no cardiac complication, although the heart's action was at first very rapid and irregular, but it soon quieted down. It was his second attack, and the first had lasted for six weeks under treatment in a hospital.

CASE 3.-C. B-C, aged twenty-three, was admitted on June 16th, 1876, with an attack of acute rheumatism affecting his right knee and elbow. His temperature was $102^{\circ}$, and fluctuated between $101^{\circ}$ and $102.4^{\circ}$ for the next three days, during which period he was taking salicin in fifteengrain doses every two hours. On the 20 th the evening temperature rose to $103^{\circ}$, but from this period the disease gradually subsided, and on the 25th the temperature was normal. There was no cardiac complication.

CASE 4.-M. L-, aged tmenty-two, was admitted on July 8th, with well-marked symptoms of rheumatic fever. He had been ill for six days, and had very extensive effusion into both knee-joints, the left especially. His ankles, wrists, metacarpal and phalangeal joints were red, swollen, and exquisitely painful. On admission his temperature was $101 \cdot 8^{\circ}$, pulse 108 , and respiration 32 . At night his temperature was $102^{\circ}$, and on the next morning it had fallen to $100 \cdot 6^{\circ}$. The apex of the heart was displaced downwards and outwards, and a systolic bruit was heard over it. He had suffered from two attacks previously, one lasting thirteen weeks, and the other four weeks. Salicin was ordered on his admission, in doses of ten grains every two hours. On the 10th the dose of salicin was increased to fifteen grains, and on the 11th to twenty grains every two hours. The swelling in the knee-joints had much diminished, but he had slept badly, and his general condition had not improved. His temperature was fluctuating between $102^{\circ}$ and $103^{\circ}$, his pulse had risen to 120 , and his respiration to 40 . On the 12th he was covered with sudamina, the heart's action was irregular and tumultuous, and on the 13th a distinct pericardial friction was heard. His urine was now alkaline, but it contained no albumen. On the 14th the rub had increased in intensity, and its loud grating to-andfro character enabled it to be felt as well as heard, whilst the area of the cardiac dulness was also a little enlarged upwards and laterally. He now complained very much of acute pain in the cardiac region, which was relieved by the application of three leeches. The salicin was still continued; poultices had been applied to the chest from the commencement of the pericarditis, and the joints wrapped in cotton-wool throughout the disease. On the 18th the pain in the chest had entirely ceased, but the cardiac dulness was still exaggerated, and the friction-sound loud and grating. The wrists and fingers were still swollen and tender, but the other joints were free from pain. The salicin was now stopped, a blister was applied over the cardiac region, and six ounces of brandy were administered daily; no other drug was given. On the 21 st the rub was less distinct, the temperature, pulse, and respiration began to lessen, and the brandy was diminished. From this time 
a tedious recovery took place, and on the 28 th the temperature became normal, but his convalescence was very prolonged.

The first three cases seemed to indicate that the salicin treatment was the true desideratum in this affection; but in the last case, the absence of any relief whatever, the supervention of a very acute pericarditis, the powerlessness of the remedy against this complication and the attendant ferer, must make us besitate before we finally accept Dr. Maclagan's dictum-" that it (salicin) seems to arrest the course of the malady as effectually as quinine cures an ague or ipecacuanha a dysentery; that, given sufficiently early and in sufficient dose, it prevents these (cardiac) complications; and that its free administration is the best means of staying their progress after they have occurred."* No objection can be taken as to the sufficiency of the dose, for the salicin had been so freely administered that the patient had taken over 800 grains in the five days before the frictionsound appeared, and his heart was most carefully examined two or three times daily. I would incidentally point out that the urine became alkaline af ter the illness had existed for some days; and I have noticed a similar condition in other cases of acute rbeumatism even when treated by mineral acids or by expectants. This must make us cautious in any inferences into which we may be led as to the effect of our drugs upon the urine in this disease.

Warwick-street, S.W.

\section{GUNSHOT INJURY TO THE MUSCULO- SPIRAL NERVE.}

BY EDMUND OWEN, F.R.C.S., ASSISTANT-SURGBON TO ST. MARY'S HOSPITAL, AND LECTURER

$$
\text { ON ANATOMY. }
$$

IN the summer of 1875 a gentleman was returning after a shooting excursion in a bay off the coast of Nova Scotia. On account of the lowness of the tide, the boat grounded about twenty yards from shore; so, stepping on to one of the bow thwarts, he tried with a heary oar to shove the boat out into deeper water. He had, for what he considered to be safety, previously placed his gun in the bows of the boat with the muzzle pointed skywards. From some cause or other the gun went off, and the charge of shot entered the inner side of the uplifted and half-bent arm. The charge passed in its course the ball of the thumb, which was thus charred, and then grazed and burnt a great part of the radial border of the forearm, and, having gone through the lower part of the biceps, effected its exit a few inches above the outer elbow. The arm at once dropped helplessly. It seems that a considerable quantity of blood was lost. The wounds themselves were comparatively painless, and the only suffering appears to have been caused by the energetic application of compresses above and below the wound.

As the station in which the accident occurred was very out of the way, it was not until the evening of the following day that a surgeon, Dr. G. E. Buckley, arrived, and he, after a slight examination, thought it advisable to do nothing until the next morning. He then adrised amputation; but the patient being strongly opposed to this, Dr. Buckley administered an anæsthetic and cleaned and dressed the wound, cutting away the damaged skin and muscle. After this, dressings were daily applied, and the patient informs me, in the graphic notes of his case with which I have been furnished, that there was a wound above the elbow large enough to receive the fist, and that the (arterial) pulsations could be marked. The patient was on his back for four weeks, and at one visit Dr. Buckley extracted nineteen flattened shot-corns.

The first wound to heal was that of the thumb, then that of the forearm. At about the tenth week the wound of exit had closed, and much later on that of entrance of the charge; one sinus remained open until last March. The limb was kept lying across the chest.

In June last the patient came to England for further

$$
\text { * Thr Laycer, Oct. 28th, } 1876 .
$$

advice, and at this time the only movement of which the injured limb was capable was flexion of the metacarpal bone of the thumb, every office which was formerly discharged by the right hand devolving upon the left.

At the end of July he was fortunate enough to come under the care of Dr. Kellgreen, of 85, St. George's-road, Pimlico, who is the director of the Swedish Institution for the Cure of Disease by Manual Treatment.

My connexion with the patient is merely this: he had a letter of introduction to Dr. Broadbent, who sent him on to me, knowing that I should be interested in the case. I carefully examined him on October 11th, and took the following notes:-

The extremity is much wasted. The forearm and hand are ever in the prone position, and the fingers are almost straight. There is a small scar over the ball of the thumb, and a large jagged one along the radial side of the forearm. The middle of the bicipital region is occupied by an extenpassed through the limb, destroying in its course the chief sive and irregular puckering, the scarred surface in places being red and hard. It showed where the charge had part of the biceps. Some of the deepest fibres of this muscle still remain, and have an evident connexion with the tendon and the semilunar fascia. The chief part of the muscle stands out prominently above the laceration, and there the arm measures nine and a half inches in girth, whilst immediately below-that is, around the cicatrixthe circumference is only seven inches. Fair pulsation can be made out in the brachial artery as far as the wound, but under the scar the pulsation is much diminished, and not much greater than that in the inferior profunda whose course can be clearly traced out. (As the patient is very thin, the course of the inferior profunda can also be followed in the sound limb.) The circumference of the left forearm just below the middle exceeds that of the damaged arm in the corresponding situation by three-quarters of an inch. The girth of the limb at the seat of the large scar is two inches and a half less than that of the opposite side in the corresponding situation.

The musculo-spiral nerve has evidently been lacerated; the mass of supinator longus cannot be detected, nor is there any power whatever of supination of the hand nor extension of the wrist. There is the scar of an old sinus at the situation of the musculo.spiral nerve, where it winds around the outside of the humerus; there the bone is only covered by integument and a cluster of shot-corns, and when these hard bodies are pressed towards the bone, the patient volunteers the information that he feels pain over the back of the hand and fingers. For some time after the accident there was no sensation over the back and outer side of the forearm, but now be there feels a pinch like the sensation that would be caused by a red-hot iron. Gentle friction is agreeable. There is still numbness over the back of the hand; he has no power over the extensors of the thumb or fingers; he has great strength in the pronator radii teres and the flexors of the wrist and fingers. The median nerve lying alongside of the brachial artery seems to have escaped injury.

Lastly, I must refer to the method of treatment to which he is submitting himself. Every week-day he attends Dr. Kellgreen for an hour, and this gentleman puts the damaged limb through all kinds of well-directed gymnastic exercises. By the courtesy of Dr. Kellgreen I was enabled to watch the course of treatment adopted. When the patient first attended be had no power or use in the limb whatever; now he can perform certain movements with it, and is steadily improving. The Doctor says that if-as regards extension of the wrist-he were to take the hand and flex and extend it rapidly he might keep on at it for an indefinite time, but that the hand would still remain "lame." So he bends the wrist, and exerting slight resistance, instructs his pupil to try to extend. This he does slowly, so that the patient may bring all his strength of will to act through the medium of the nerve which supplies the muscles. After spending some time in this exercise he places a book in the damaged hand, and he himself holds up the wrist in a vertical position. Then, having fixed all the patient's attention on the book, he says, "Lower the book slowly." So the book and hand bend slowly forwards, till, with a trembling at the back of the wrist, it seems as if the extensors can no longer struggle against the weight. Then he stamps on the floor, and making use of some 